\title{
Dietary ascorbic acid raises iron absorption in anaemic rats through enhancing mucosal iron uptake independent of iron solubility in the digesta
}

\author{
BY K. J. H. WIENK ${ }^{1}$, J. J. M. MARX ${ }^{2}$, M. SANTOS $^{2}$, A. G. LEMMENS ${ }^{1}$, \\ E. J. BRINK ${ }^{3 *}$, R. VAN DER MEER ${ }^{4}$ AND A. C. BEYNEN ${ }^{1}$ \\ ${ }^{1}$ Department of Laboratory Animal Science, Utrecht University, PO Box 80.166, 3508 TD Utrecht, \\ The Netherlands \\ ${ }^{2}$ Eijkman-Winkler Institute and Department of Internal Medicine, University Hospital Utrecht, \\ The Netherlands \\ ${ }^{3}$ Unilever Research Laboratorium, Vlaardingen, The Netherlands \\ ${ }^{4}$ Netherlands Institute for Dairy Research, Ede, The Netherlands
}

(Received 28 February 1996-Revised 14 May 1996 - Accepted 10 June 1996)

\begin{abstract}
We studied $\mathrm{Fe}$ absorption from $\mathrm{FeSO}_{4}$ in rats with $\mathrm{Fe}$ deficiency-induced anaemia that were given an Fe-sufficient purified diet without or with ascorbic acid (10.4 $\mathrm{g} / \mathrm{kg}$ diet). Attention was focused on mucosal $\mathrm{Fe}$ uptake as measured in vivo by a double-isotope technique. Haemoglobin repletion and liver $\mathrm{Fe}$ levels were not affected when the ascorbic acid-supplemented diet was given, but apparent Fe absorption and retention of orally administered ${ }^{59} \mathrm{Fe}$ were significantly enhanced. The distribution of $\mathrm{Fe}$ between liquid and solid phases of contents of both the stomach and the proximal intestine was not affected by the feeding of the ascorbic acid, but ascorbic acid significantly enhanced mucosal Fe uptake. It is concluded that ascorbic acid in the diet raises mucosal Fe uptake through a mechanism independent of the intestinal Fe solubility.
\end{abstract}

Non-haem iron: Ascorbic acid: Anaemia

Ascorbic acid is a powerful enhancer of non-haem Fe absorption in man (Monsen, 1982; Hallberg et al. 1986). The mechanism of action of ascorbic acid is not yet fully clear. In the digesta, ascorbic acid may reduce ferric iron to the ferrous form (Bothwell et al. 1979), which should raise Fe solubility (Van Gils et al. 1994) and thereby render Fe available for absorption in the proximal intestine. Alternatively, ascorbic acid may facilitate $\mathrm{Fe}$ absorption by forming with Fe a chelate that is soluble in the digesta (Bothwell et al. 1979; Lynch \& Cook, 1980), but this mechanism has been criticized (Plug et al. 1984).

It is not known whether ascorbic acid has any effect on processes beyond intraluminal interaction, i.e. at the level of the microvillous mucosal membrane or within the enterocyte. Dietary modulators of $\mathrm{Fe}$ absorption could influence mucosal $\mathrm{Fe}$ uptake and/or mucosal transfer. For instance, we have shown in rats that $\mathrm{CaCO}_{3}$ inhibits Fe absorption, at least partly, by reducing mucosal Fe transfer (Wienk et al. 1996). In this present study we focused on the effect of dietary ascorbic acid on mucosal uptake of Fe. In keeping with our previous study (Wienk et al. 1996) we used as a model the anaemic rat being repleted with Fe.

\footnotetext{
* Present address: Institute for Animal Science and Health, Lelystad, The Netherlands.
} 


\section{MATERIALS AND METHODS}

The experimental protocol was approved by the Animal Experiments Committee of the Department of Laboratory Animal Science, Utrecht University, The Netherlands.

\section{Animals, housing and diets}

Weanling, male Wistar U:WU(CPB) rats, aged about 3 weeks, were used. For 3 weeks the rats were housed in groups of four animals in wire-topped polycarbonate cages (Macrolon Type III, UNO B.V., Zevenaar, The Netherlands), containing a layer of Fe-free sawdust. Subsequently they were transferred to metabolism cages (Tecniplast Gazzada, Buguggiate, Italy) in which they were housed individually for the remaining 3 weeks of the study. All rats were housed in a room with controlled temperature $\left(20-22^{\circ}\right)$, relative humidity (40-65\%) and lighting $(12 \mathrm{~h} / \mathrm{d})$.

During the first 4 weeks the rats were fed on a pre-experimental, purified diet which was low in $\mathrm{Fe}$ in order to induce Fe-deficiency anaemia (Table 1). While the rats were housed in groups they had free access to their diet. From the time-point of individual housing they were accustomed to a time-restricted feeding regimen. They had free access to feed, but only for $4 \mathrm{~h} / \mathrm{d}(08.00-12.00$ hours). Demineralized water was supplied ad libitum throughout the study. All animals were weighed weekly.

At the end of the 4-week pre-experimental period (day 0 ) the animals were divided into two groups of eight rats each, so that the group distributions of blood haemoglobin $(\mathrm{Hb})$ and body weight were similar. Each group was fed on one of the two experimental, purified diets (Table 1). The rats were assigned a randomized cage position. We supplied a control diet and an ascorbic acid-containing diet $(10 \mathrm{~g}$ ascorbic acid $/ \mathrm{kg}$ diet; L-ascorbic acid, Merck, Darmstadt, Germany). The diets were in powdered form, and stored at $4^{\circ}$ until used for feeding. The experimental diets were made adequate in $\mathrm{Fe}$ by the addition of $\mathrm{FeSO}_{4} \cdot 7 \mathrm{H}_{2} \mathrm{O}$. Feed intake was recorded daily, and water intake was recorded during two $3 \mathrm{~d}$ balance periods (days 5-7 and 12-14). The experimental period lasted for $15 \mathrm{~d}$.

Table 1. Composition of the pre-experimental and experimental diets

\begin{tabular}{|c|c|c|c|}
\hline \multirow[t]{2}{*}{ Diet ... } & \multirow[t]{2}{*}{ Pre-experimental } & \multicolumn{2}{|c|}{ Experimental } \\
\hline & & Control & Ascorbic acid \\
\hline \multicolumn{4}{|c|}{ Variable ingredients (per kg diet) } \\
\hline Glucose $(\mathrm{g})$ & $704 \cdot 3$ & $704 \cdot 1$ & $694 \cdot 1$ \\
\hline $\mathrm{FeSO}_{4} .7 \mathrm{H}_{2} \mathrm{O}(\mathrm{mg})$ & - & 174 & 174 \\
\hline Ascorbic acid $(\mathrm{g})$ & - & - & 10 \\
\hline Constant ingredients* (g) & 295.7 & 295.7 & 295.7 \\
\hline \multicolumn{4}{|c|}{ Chemical analysis (per kg diet) } \\
\hline Iron $(\mathrm{mg})$ & 5.6 & 43.0 & 44.4 \\
\hline Vitamin C (g) & nd & nd & 10.4 \\
\hline
\end{tabular}

nd, not determined

* Constant components consisted of (g): casein 151 , maize oil 25 , coconut fat 25 , cellulose $30, \mathrm{CaCO}_{3} 12 \cdot 5$, $\mathrm{MgCO}_{3} 1.4, \mathrm{NaH}_{2} \mathrm{PO}_{4} .2 \mathrm{H}_{2} \mathrm{O} 20 \cdot 1, \mathrm{KCl} 1.0, \mathrm{KHCO}_{3} 7.7$, Fe-free mineral premix 10, vitamin premix 12. Mineral and vitamin premixes are specified elsewhere (Wienk et al. 1996). 


\section{Ascorbic acid analysis}

Ascorbic acid was determined in the ascorbic-acid diet according to the method of Speek et al. (1984).

\section{Haemoglobin determination}

On day 0 and day 15 of the experimental period, blood was withdrawn by orbital puncture while the rats were under light diethyl ether anaesthesia. About $0.8 \mathrm{ml}$ blood was collected from each animal. Hb was determined using a haematology analyser (Sysmex K-1000, Toa Medical Electronics Co. Ltd, Kobe, Japan).

\section{Iron analysis}

Diets were wet-ashed in 14.3 $\mathrm{M}-\mathrm{HNO}_{3}$ and $\mathrm{Fe}$ was determined by flame atomic absorption spectrometry (Varian SpectrAA 250 Plus, Varian, Mulgrave Victoria, Australia Pty Ltd).

Faeces were collected quantitatively for individual animals during the two $3 \mathrm{~d}$ balance periods (days 5-7 and 12-14). Metabolism cages and excreta collection tubes were rinsed with $0.1 \mathrm{M}-\mathrm{HCl}$ and demineralized water before use to prevent $\mathrm{Fe}$ contamination. Faeces were pooled for each rat during each balance period, dried $\left(75^{\circ}, 70 \mathrm{~h}\right)$, and dry-ashed $\left(500^{\circ}\right.$, $17 \mathrm{~h}$ ). The ash was dissolved in $6 \mathrm{M}-\mathrm{HCl}$ and $\mathrm{Fe}$ analysed in the resulting acid extracts using flame atomic absorption spectrometry.

On day 15 all rats received their diets with or without supplemental ascorbic acid at 10 min time intervals. Exactly $3 \mathrm{~h}$ after the start of feed supply, each rat was killed by cervical dislocation while under light diethyl ether anaesthesia. The stomach and the entire small intestine were removed. The latter was divided into proximal and distal halves. Digesta samples were collected in pre-weighed centrifuge tubes, weighed, and centrifuged (stomach digesta: $30 \mathrm{~min}, 40000 \mathrm{~g}$; intestinal digesta: $5 \mathrm{~min}, 8000 \mathrm{~g}$ ). The supernatant and pellet fractions were separated and weighed. The $\mathrm{pH}$ of the supernatant fraction was measured (Russell combination pH electrode, Type RS-53, Auchtermuchty, Fife). The stomach supernatant fraction was then diluted twice in a $0.2 \mathrm{M}-\mathrm{HCl}$ solution, mixed, centrifuged $(5 \mathrm{~min}, 8000 \mathrm{~g})$ and $\mathrm{Fe}$ was determined in the supernatant fraction. The proximal intestinal supernatant fraction was diluted fivefold with a $0.2 \mathrm{M}-\mathrm{HCl}$ solution. The mixture was centrifuged $(5 \mathrm{~min}, 8000 \mathrm{~g}$ ) and $\mathrm{Fe}$ was determined in the supernatant fraction. The pellet was freeze-dried, weighed, dry-ashed $\left(17 \mathrm{~h}, 500^{\circ}\right)$, dissolved in $6 \mathrm{M}-\mathrm{HCl}$, and brought to a final concentration of $1.2 \mathrm{M}-\mathrm{HCl}$ with demineralized water. Because of the minute amounts of sample, Fe was determined using a commercial kit (Iron FZ Test, Roche, Hoffmann La Roche \& Co Ltd, Diagnostica, Basle, Switzerland) on a COBAS-BIO auto-analyser (Hoffmann-La Roche BV, Mijdrecht, The Netherlands) instead of using flame absorption spectrometry. The results of the two methods had been found earlier to correlate well $(r 0.88 ; P=0.01)$. Correlations were made for the amount of supernatant fraction that was still present in the pellet fraction before dry-ashing. Supernatant and freeze-dried pellet fractions of the digesta are referred to as liquid and solid phases of the digesta respectively.

Immediately after the rats had been killed, livers were removed, rinsed in saline $(9 \mathrm{~g}$ $\mathrm{NaCl} / 1)$ to remove blood, patted dry, weighed and frozen at $-20^{\circ}$ until analysis. A portion of liver (about $2 \mathrm{~g}$ ) was dried overnight $\left(105^{\circ}\right)$, dry-ashed $\left(17 \mathrm{~h}, 500^{\circ}\right)$, dissolved in $6 \mathrm{M}$ $\mathrm{HCl}$, and $\mathrm{Fe}$ was determined using flame atomic absorption spectrometry. 


\section{Mucosal ${ }^{59} \mathrm{Fe}$ uptake, transfer and retention}

On day 8, all rats received a ${ }^{59} \mathrm{Fe}^{2+}$ - and ${ }^{51} \mathrm{Cr}^{3+}$-containing suspension of their respective diets. Demineralized water and the respective diet were mixed $(1: 1, \mathrm{w} / \mathrm{w})$ and spiked with ${ }^{51} \mathrm{Cr}^{3+}$ chloride and ${ }^{59} \mathrm{Fe}^{3+}$ citrate, which had been reduced to ${ }^{59} \mathrm{Fe}^{2+}$ with an equimolar amount of ascorbic acid. The amount of ascorbic acid used to reduce ferrous Fe was only $0.01 \%$ of the amount ingested each day by the rats in the ascorbic-acid group. The resulting suspensions were swirled continuously during sampling. Samples of approximately $2 \mathrm{~g}$ were administered orally to each rat with the use of an oroesophageal needle. Each rat ingested about $55 \mathrm{kBq}{ }^{59} \mathrm{Fe}$ and $220 \mathrm{kBq}{ }^{51} \mathrm{Cr}$.

At $1 \mathrm{~h}$ after dosing, whole-body ${ }^{59} \mathrm{Fe}$ and ${ }^{51} \mathrm{Cr}$ radioactivities were measured simultaneously in each rat using a whole-body gamma counter (Automatic Scanner DS4/ 4S, Tracerlab Ltd, Weybridge, Surrey). The amounts of radioactivity measured were regarded as the $100 \%$ values. The gamma counter had separate detection windows for ${ }^{59} \mathrm{Fe}$ and ${ }^{51} \mathrm{Cr}$ peaks. Corrections for ${ }^{59} \mathrm{Fe}$ in the ${ }^{51} \mathrm{Cr}$ window were made. Whole-body radioactivity determinations were repeated daily for a period of $7 \mathrm{~d}$. The values were corrected for radioisotope decay and day-to-day fluctuations of the scanner with the use of a Ra source.

${ }^{51} \mathrm{Cr}$ was administered together with ${ }^{59} \mathrm{Fe}$ to measure mucosal uptake and mucosal transfer of ${ }^{59} \mathrm{Fe}$. The method is based on the fact that the absorption of ${ }^{51} \mathrm{Cr}$ is negligible. The fraction of ${ }^{51} \mathrm{Cr}$ that is measured in the animal will be located in the gastrointestinal lumen. At $2 \mathrm{~d}$ after ingestion, part of the ${ }^{51} \mathrm{Cr}$ will be in the caecum and the colon, the other fraction having been defaecated. The fraction of ${ }^{59} \mathrm{Fe}$ in the animal after $2 \mathrm{~d}$ will be either absorbed or present in the lumen of the caecum and colon. If the transit times of both isotopes are similar, it follows that:

$$
\text { faecal }{ }^{51} \mathrm{Cr} / \text { faecal }{ }^{59} \mathrm{Fe}=\text { lumen }{ }^{51} \mathrm{Cr} / \text { lumen }{ }^{59} \mathrm{Fe} \text {, }
$$

where all terms are expressed as a percentage of intake. Because the percentages of faecal ${ }^{51} \mathrm{Cr}$ and ${ }^{59} \mathrm{Fe}$ can be measured (i.e. $100 \%$ values minus ${ }^{51} \mathrm{Cr}$ and ${ }^{59} \mathrm{Fe}$ retained at $2 \mathrm{~d}$ ), and because faecal ${ }^{51} \mathrm{Cr}+$ lumen ${ }^{51} \mathrm{Cr}$ adds up to $100 \%$, the percentage of lumen ${ }^{59} \mathrm{Fe}$ can be calculated. Subtraction of the percentage of lumen ${ }^{59} \mathrm{Fe}$ from the percentage of ${ }^{59} \mathrm{Fe}$ that is measured in the animal then results in a value for the absorbed portion of ${ }^{59} \mathrm{Fe}$, which is defined as mucosal Fe uptake. Theoretically, the final ${ }^{59} \mathrm{Fe}$ retention is less than or equal to the mucosal Fe uptake, because some of the ${ }^{59} \mathrm{Fe}$ that was initially absorbed may become trapped in the mucosa, leaving the body when the mucosa is desquamated. Final ${ }^{59} \mathrm{Fe}$ retention was corrected for any remaining ${ }^{51} \mathrm{Cr}, 7 \mathrm{~d}$ after dosing. The final ${ }^{59} \mathrm{Fe}$ retention: mucosal ${ }^{59} \mathrm{Fe}$ uptake ratio is defined as mucosal ${ }^{59} \mathrm{Fe}$ transfer. The technique and calculations are described in detail by Marx (1979).

\section{Statistical analysis}

Results are presented as means with their standard errors. All data were found to be normally distributed according to the Kolmogorov-Smirnov one-sample test, with $P=0.05$ as cut-off value. Student's $t$ test was used for comparisons between the control and ascorbic-acid groups. The level of significance was pre-set at $P<0.05$. All statistical analyses were conducted with the use of SPSS/PC+ software (Statistical Package for the Social Sciences, 1988). 


\section{RESULTS}

\section{Growth, feed and water intake}

Mean body weight at day 0 was 145 (SE 4) g ( $n$ 16). Feed and water intakes, body-weight gain and final liver weight did not differ significantly between the two groups. Mean feed intake was 11.0 (SE 2.0) $\mathrm{g} / \mathrm{d}(n 16)$, water intake was 14 (SE 1) $\mathrm{ml} / \mathrm{d}$, body-weight gain (days $0-15$ ) was 34.2 (SE 2.0) g/15 d, and liver weight at day 15 was 33.7 (SE 0.3 ) g/kg body weight.

\section{Iron status}

All rats had anaemia after they had been fed on the pre-experimental diet for 4 weeks: mean blood $\mathrm{Hb}$ level was 4.3 (SE 0.1) mmol/l (69 g/l) ( $n$ 16). After 2 weeks on the experimental diets both groups showed a recovery from the anaemia. There was no significant difference between the control and ascorbic-acid groups, their mean $\mathrm{Hb}$ values being 9.4 (SE 0.1) and 9.3 (SE 0.1) mmol/l ( $n$ 8). Likewise, the Fe content of liver was not influenced by ascorbic acid addition to the diet. Hepatic Fe concentrations were 361 (SE 28) and 447 (SE 86) $\mu \mathrm{g} / \mathrm{g}$ dry weight $(n 8)$ for the control and test groups respectively.

\section{Iron balance}

Fe intake, faecal excretion and apparent absorption are listed in Table 2. Apparent $\mathrm{Fe}$ absorption was high during days 5-7, but had declined after 12-14 d. During the first period, apparent Fe absorption was significantly increased by ascorbic acid, resulting in a lower faecal Fe excretion. During days 12-14, there was no longer a significant effect of ascorbic acid.

Table 2. Iron intake, faecal iron excretion and apparent iron absorption in rats with irondeficiency induced anaemia and subsequently (from day 0) fed for $15 d$ on an iron-sufficientd diet without or with ascorbic acid $\dagger$

(Mean values with their standard errors for eight animals per group)

\begin{tabular}{|c|c|c|c|c|}
\hline \multirow[t]{2}{*}{ Diet ... } & \multicolumn{2}{|c|}{ Control } & \multicolumn{2}{|c|}{ Ascorbic acid } \\
\hline & Mean & SEM & Mean & SEM \\
\hline \multicolumn{5}{|l|}{ Iron balance, days $5-7$} \\
\hline Intake $(\mu \mathrm{g} / \mathrm{d})$ & 478 & 14 & 492 & 24 \\
\hline Faecal excretion $(\mu \mathrm{g} / \mathrm{d})$ & 56 & 6 & $37^{*}$ & 3 \\
\hline Apparent absorption ( $\%$ of intake) & $88 \cdot 3$ & 1.2 & $92.4 *$ & 0.6 \\
\hline \multicolumn{5}{|l|}{ Iron balance, days $12-14$} \\
\hline Intake $(\mu \mathrm{g} / \mathrm{d})$ & 533 & 12 & 558 & 19 \\
\hline Faecal excretion $(\mu \mathrm{g} / \mathrm{d})$ & 187 & 20 & 176 & 36 \\
\hline Apparent absorption ( $\%$ of intake) & $65 \cdot 1$ & 3.4 & 68.6 & $6 \cdot 1$ \\
\hline
\end{tabular}

* Mean values were significantly different from those for control group (two-tailed Student's $t$ test), $P<0.05$.

$\dagger$ For details of diets and procedures, see Table 1 and pp. 124-126. 


\section{Mucosal uptake, transfer and retention of ${ }^{59} \mathrm{Fe}$}

With the use of ${ }^{59} \mathrm{Fe}$ and ${ }^{51} \mathrm{Cr}$ we found a group mean mucosal ${ }^{59} \mathrm{Fe}$ uptake of $80.1 \%$ and ${ }^{59} \mathrm{Fe}$ retention of $81.0 \%$ in control rats, indicating that all $\mathrm{Fe}$ taken up by the mucosa was retained (Table 3 ). The rats given ascorbic acid showed a significantly higher mucosal uptake and retention of ${ }^{59} \mathrm{Fe}$, but mucosal transfer was unaltered. At day 15 (7 d after administration), ${ }^{51} \mathrm{Cr}$ retention was 2.8 (SE 0.2) and 3.9 (SE 0.6) \% of the administered dose for the control and ascorbic-acid groups respectively. This difference was not statistically significant.

\section{Iron solubility in digesta}

Neither in the stomach nor in the proximal half of the small intestine did we find group differences in Fe contents of the solid and liquid digesta fractions (Table 4). Likewise, the Fe concentration of the liquid phase, an index of Fe solubility, did not differ between the control and test rats. The liquid contents of the stomach had a lower $\mathrm{pH}$ when ascorbic acid was fed, but no difference was seen in the proximal intestine. The relative amount of solid phase in the stomach contents was higher than in the intestinal contents. Possibly, the difference relates to sample preparation. Because of the high viscosity, the stomach contents had to be centrifuged longer and faster than the intestinal contents. Thus, we did not compare Fe concentrations in stomach and intestinal contents.

\section{DISCUSSION}

As would be expected, the feeding of ascorbic acid significantly raised the efficiency of Fe absorption. Apparent Fe absorption was significantly enhanced by ascorbic acid between days 5 and 7 after Fe repletion. ${ }^{59}$ Fe retention, which essentially equals Fe absorption, was significantly enhanced, also, by dietary ascorbic acid. The percentage apparent $\mathrm{Fe}$ absorption between days 5 and 7 was slightly higher than the percentage ${ }^{59} \mathrm{Fe}$ retention as based on a single dose administered on day 8 . The difference in values for the two absorption measurements relates to the improvement of Fe status in the course of the experimental period when Fe sufficient diets were fed. It is known that an increase in $\mathrm{Fe}$ status leads to a decrease in Fe absorption, which is reflected also by the lower apparent $\mathrm{Fe}$ absorption during days 12-14, when compared with days 5-7. The feeding of ascorbic acid

Table 3. Mucosal uptake, mucosal transfer and retention of a single dose of ${ }^{59} \mathrm{Fe}$ that was orally supplied (at day 8) to rats with iron-deficiency-induced anaemia and subsequently (from day 0) fed for $15 d$ on an iron-sufficient diet without or with ascorbic acid $\dagger$

(Mean values with their standard errors for eight animals per group)

\begin{tabular}{|c|c|c|c|c|}
\hline \multirow[t]{2}{*}{ Diet ... } & \multicolumn{2}{|c|}{ Control } & \multicolumn{2}{|c|}{ Ascorbic acid } \\
\hline & Mean & SEM & Mean & SEM \\
\hline Mucosal ${ }^{59} \mathrm{Fe}$ uptake (\% of administered dose) & $80 \cdot 1$ & $2 \cdot 7$ & $89.7^{*}$ & 0.9 \\
\hline Mucosal ${ }^{59} \mathrm{Fe}$ transfer (retained fraction of mucosal ${ }^{59} \mathrm{Fe}$ uptake) & 1.01 & 0.01 & 0.99 & 0.01 \\
\hline${ }^{59} \mathrm{Fe}$ retention at $7 \mathrm{~d}$ post-administration ( $\%$ of administered dose) & 81.0 & $2 \cdot 7$ & $89 \cdot 2^{*}$ & 1.4 \\
\hline
\end{tabular}

* Mean values were significantly different from those for control group (two-tailed Student's $t$ test), $P<0.05$.

$\dagger$ For details of diets and procedures, see Table 1 and pp. 124-126. 
Table 4. Distribution of iron between solid and liquid digesta fractions of stomach and proximal intestine from rats with iron-deficiency-induced anaemia and subsequently fed for $15 d$ on an iron-sufficient diet without or with ascorbic acid. $\dagger$

(Mean values with their standard errors for eight animals per group, except for $\mathrm{pH}$ in the intestinal liquid phase, which is for seven and five animals)

\begin{tabular}{|c|c|c|c|c|}
\hline \multirow{2}{*}{ Diet ... } & \multicolumn{2}{|c|}{ Control } & \multicolumn{2}{|c|}{ Ascorbic acid } \\
\hline & Mean & SEM & Mean & SEM \\
\hline \multicolumn{5}{|l|}{ Stomach } \\
\hline Solid phase freeze-dried wt (g) & 3.65 & 0.53 & 3.87 & 0.59 \\
\hline Liquid phase wt (g) & 3.46 & 0.52 & 4.76 & 0.60 \\
\hline Liquid phase $\mathrm{pH}$ & 5.46 & 0.08 & $5 \cdot 24 *$ & 0.06 \\
\hline $\mathrm{Fe}$ in solid phase $(\mu \mathrm{g})$ & 178 & 27 & 191 & 26 \\
\hline Fe in liquid phase $(\mu \mathrm{g})$ & 4.2 & 0.5 & 4.3 & 0.7 \\
\hline Fe concentration in liquid phase $(\mu \mathrm{g} / \mathrm{g})$ & $1 \cdot 30$ & $0 \cdot 19$ & 0.95 & 0.19 \\
\hline \multicolumn{5}{|l|}{ Proximal intestine } \\
\hline Solid phase freeze-dried wt (mg) & 8.86 & 1.36 & 12.80 & $2 \cdot 21$ \\
\hline Liquid phase wt (mg) & 218 & 28 & 237 & 47 \\
\hline Liquid phase $\mathrm{pH}$ & $6 \cdot 19$ & 0.04 & $6 \cdot 15$ & 0.20 \\
\hline Fe in solid phase $(\mu \mathrm{g})$ & 1.23 & 0.29 & 1.70 & 0.20 \\
\hline Fe in liquid phase $(\mu \mathrm{g})$ & 0.55 & 0.09 & 0.60 & $0 \cdot 13$ \\
\hline Fe concentration in liquid phase $(\mu \mathrm{g} / \mathrm{g})$ & 2.76 & 0.41 & 2.45 & 0.22 \\
\hline
\end{tabular}

* Mean value was significantly different from that for control group, $P<0.05$ (two-tailed Student's $t$ test).

$\uparrow$ For details of diets and procedures, see Table 1 and pp. 124-126.

did not significantly raise apparent Fe absorption between days 12 and 14, but this may be attributed to the substantial inter-individual variation.

Unexpectedly, ascorbic acid ingestion did not produce higher $\mathrm{Hb}$ and hepatic $\mathrm{Fe}$ concentrations. Ascorbic acid may have increased the initial rates by which $\mathrm{Hb}$ and hepatic Fe increased during Fe repletion without affecting the final values. The rats were given, daily, about $0.43 \mathrm{~g}$ ascorbic acid $/ \mathrm{kg}$ metabolic weight, which is equivalent to a daily intake of about $10 \mathrm{~g}$ in man, this amount being about 160 times higher than the recommended dietary allowance. Daily supplementation with $1.5 \mathrm{~g}$ ascorbic acid leads to significantly higher $\mathrm{Hb}$ gain in Fe-depleted humans (Hunt et al. 1990). Thus, our rats only showed a small response to dietary ascorbic acid when compared with humans, which confirms earlier work (Reddy \& Cook, 1991). The hyporesponsiveness of rats to ascorbic acid may relate to their capacity to synthesize ascorbic acid. In a rat strain lacking ascorbic-acidsynthesizing capacity, Fe absorption was strongly enhanced after addition of ascorbic acid to the diet (Reddy \& Cook, 1994).

The anaemic-rat model has an intrinsic, high efficiency of $\mathrm{Fe}$ absorption so that any modulation by a dietary factor can be easily masked. By exposure of the rat model to a high amount of ascorbic acid it was possible to raise Fe absorption which in turn allowed us to study the mechanism underlying the effect of ascorbic acid. Ascorbic acid is thought to increase Fe absorption because of its reducing properties (Bothwell et al. 1979; Barrand et al. 1990), by which it converts and keeps Fe in the ferrous state. Dietary ferrous $v$. ferric Fe elevates the concentration of $\mathrm{Fe}$ in the liquid phase of the digesta and therefore is more available for absorption (Van Gils et al. 1994). In the present study, using diets supplemented with $\mathrm{FeSO}_{4}$, the feeding of ascorbic acid did not affect the concentration of $\mathrm{Fe}$ in the liquid phase of contents of the proximal intestine. Apparently, in the control situation there were already sufficient ligands retaining the Fe in the soluble phase so that 
additional reducing capacity in the form of ascorbic acid had no effect. The observed increase in Fe absorption in rats given ascorbic acid, when compared with the high values in the control rats, appears to be independent of the solubility of $\mathrm{Fe}$ in the digesta. The rats were given purified diets. If natural-ingredient diets had been used ascorbic acid could have had an additional effect by counteracting components that inhibit $\mathrm{Fe}$ absorption by reducing Fe solubility in the digesta. In vitro, ascorbic acid has been shown to antagonize the inhibitory effect of soyabean-protein isolate on Fe solubilization (Rizk \& Clydesdale, 1983). In man, ascorbic acid consumption counteracted the inhibitory effect of phytate on Fe absorption (Hallberg et al. 1989).

It has been demonstrated, using rabbit duodenal microvillous membrane vesicles, that ferric $\mathrm{Fe}$ may bind to the membrane but is not transported, whereas ferrous Fe, in the form of ferrous ascorbate, is readily transported (Marx \& Aisen, 1981). There is evidence that the mucosal cell itself provides the reducing capacity to allow transport of $\mathrm{Fe}$, in the ferrous form, across the microvillous membrane. This reducing capacity for Fe may be enhanced in Fe deficiency as indicated by the increased Fe transport across brush-border membranes isolated from Fe-deficient mice (Muir et al. 1984). Stremmel et al. (1987) identified, in rat duodenal microvillous membrane vesicles, a $52 \mathrm{kDa}$ Fe-transport protein, possibly a reductase, that may function as a carrier for Fe. Thus, even at maximum induction of the reducing capacity of the mucosal cells, ascorbic acid is able to enhance Fe uptake. As stated earlier, ascorbic-acid feeding did not raise the amount of soluble $\mathrm{Fe}$, i.e. the amount of $\mathrm{Fe}$ available for uptake through the microvillous mucosal membrane. It is possible that ascorbic acid acts directly at the level of the membrane. Alternatively, ascorbic acid could influence the form of soluble $\mathrm{Fe}$. Fe in the liquid phase of the digesta consists of ferrous and ferric Fe species (Wollenberg \& Rummel, 1987; Simpson \& Peters, 1990). Possibly, in the ascorbic-acid-fed group there was a higher proportion of ferrous $\mathrm{Fe}$, but the total amount of soluble $\mathrm{Fe}$ in the digesta was not affected.

The $\mathrm{Fe}$ absorption process can be divided into mucosal uptake, i.e. transport across the microvillous membrane of mucosal cells, and mucosal transfer, i.e. transport through the mucosal cytoplasm and across the basolateral plasma membrane into the plasma (Manis \& Schachter, 1962; Marx, 1979). With the use of orally administered ${ }^{59} \mathrm{Fe}$ and ${ }^{51} \mathrm{Cr}$, as a nonabsorbable marker, we determined mucosal uptake and transfer of Fe. Ascorbic acid loading was found to stimulate mucosal Fe uptake, but there was no effect of ascorbic acid on mucosal $\mathrm{Fe}$ transfer. It is not possible to observe any stimulatory effect of ascorbic acid on intramucosal $\mathrm{Fe}$ handling or $\mathrm{Fe}$ transport across the basolateral plasma membrane as this $\mathrm{Fe}$ transport is already maximal in $\mathrm{Fe}$ deficiency. Studies using adult rats with a high $\mathrm{Fe}$ status may reveal an effect of ascorbic acid on mucosal Fe transfer, if any.

This study was supported by Unilever Research Laboratorium, Vlaardingen, The Netherlands, through grant PAD 90-66 of the Dutch Platform for Alternatives to Animal Experiments.

\section{REFERENCES}

Barrand, M. A., Hider, R. C. \& Callingham, B. A. (1990). The importance of reductive mechanisms for intestinal uptake of iron from ferric maltol and ferric nitrilotriacetic acid (NTA). Journal of Pharmacy and Pharmacology 42, 279-282.

Bothwell, T. H., Charlton, R. W., Cook, J. D. \& Finch, C. A. (1979). Iron absorption. In Iron Metabolism in Man, pp. 256-283. Oxford: Blackwell Scientific Publications.

Hallberg, L., Brune, M. \& Rossander, L. (1986). Effect of ascorbic acid on iron absorption from different types of meals. Studies with ascorbic-acid-rich foods and synthetic ascorbic acid given in different amounts with different meals. Human Nutrition: Applied Nutrition 40A, 97-113. 
Hallberg, L., Brune, M. \& Rossander, L. (1989). Iron absorption in man: ascorbic acid and dose-dependent inhibition by phytate. American Journal of Clinical Nutrition 49, 140-144.

Hunt, J. R., Mullen, L. M., Lykken, G. I., Gallagher, S. K. \& Nielsen, F. H. (1990). Ascorbic acid: effect on ongoing iron absorption and status in iron-depleted young women. American Journal of Clinical Nutrition 51, 649655.

Lynch, S. R. \& Cook, J. D. (1980). Interaction of vitamin C and iron. Annals of the New York Academy of Sciences 355, 32-44.

Manis, J. G. \& Schachter, D. (1962). Active transport of iron by intestine: features of the two-step mechanism. American Journal of Physiology 203, 73-80.

Marx, J. J. M. (1979). Mucosal uptake, mucosal transfer and retention of iron, measured by whole-body counting. Scandinavian Journal of Haematology 23, 293-302.

Marx, J. J. M. \& Aisen, P. (1981). Iron uptake by rabbit intestinal mucosal membrane vesicles. Biochimica et Biophysica Acta 649, 297-304.

Monsen, E. R. (1982). Ascorbic acid: an enhancing factor in iron absorption. In Nutritional Bioavailability of Iron. ACS Symposium Series no. 203, pp. 85-95 [C. Kies, editor]. Washington, DC: American Chemical Society.

Muir, W. A., Hopfer, U. \& King, M. (1984). Iron transport across brush-border membranes from normal and iron-deficient mouse upper small intestine. Journal of Biological Chemistry 259, 4896-4903.

Plug, C. M., Dekker, D. \& Bult, A. (1984). Complex stability of ferrous ascorbate in aqueous solution and its significance for iron absorption. Pharmaceutisch Weekblad Scientific Edition 6, 245-248.

Reddy, M. B. \& Cook, J. D. (1991). Assessment of dietary determinants of nonheme-iron absorption in humans and rats. American Journal of Clinical Nutrition 54, 723-728.

Reddy, M. B. \& Cook, J. D. (1994). Absorption of nonheme iron in ascorbic acid-deficient rats. Journal of Nutrition 124, 882-887.

Rizk, S. W. \& Clydesdale, F. M. (1983). Effect of iron sources and ascorbic acid on the chemical profile of iron in a soy protein isolate. Journal of Food Science 48, 1431-1435.

Simpson, R. J. \& Peters, T. J. (1990). Forms of soluble iron in mouse stomach and duodenal lumen: significance for mucosal uptake. British Journal of Nutrition 63, 79-89.

Speek, A. J., Schrijver, J. \& Schreurs, W. H. P. (1984). Fluorometric determination of total vitamin C and total isovitamin $\mathrm{C}$ in foodstuffs and beverages by high-performance liquid chromatography with precolumn derivatization. Journal of Agricultural and Food Chemistry 32, 352-355.

Statistical Package for the Social Sciences (1988). SPSS/PC+ V2.0 Base Manual. Chicago, IL: SPSS Inc.

Stremmel, W., Lotz, G., Niederau, C., Teschke, R. \& Strohmeyer, G. (1987). Iron uptake by rat duodenal microvillous membrane vesicles: evidence for a carrier mediated transport system. European Journal of Clinical Investigation 17, 136-145.

Van Gils, A. P. M., Lemmens, A. G. \& Beynen, A. C. (1994). Fructose versus glucose in the diet of rats lowers the apparent absorption of dietary iron from both ferrous and ferric sulphate. Journal of Animal Physiology and Animal Nutrition 71, 22-29.

Wienk, K. J. H., Marx, J. J. M., Lemmens, A. G., Brink, E. J., Van der Meer, R. \& Beynen, A. C. (1996). Mechanism underlying the inhibitory effect of high calcium carbonate intake on iron bioavailability from ferrous sulphate in anaemic rats. British Journal of Nutrition 75, $109-120$.

Wollenberg, P. \& Rummel, W. (1987). Dependence of intestinal iron absorption on the valency state of iron. Naunyn-Schmiedeberg's Archives of Pharmacology 336, 578-582. 